\begin{tabular}{|c|c|c|c|c|c|c|c|}
\hline & Oh & & & & & & \\
\hline$B J A B$ & -Tet & + Tet & Pattern & Clone1 (normalized reads $>10$ ) & Clone2 (normalized reads $>10$ ) & Clone1 $(\mathrm{fdr}<0.05)$ & Clone2(fdr<0.05) \\
\hline & & & 1 & 9517 & 10357 & & 0 \\
\hline & & & 2 & 53 & 64 & 41 & 43 \\
\hline & & & 3 & 38 & 33 & 26 & 18 \\
\hline & & & 4 & 7701 & 5583 & 6329 & 4424 \\
\hline & & & 5 & 163 & 66 & 159 & 65 \\
\hline
\end{tabular}

B

C

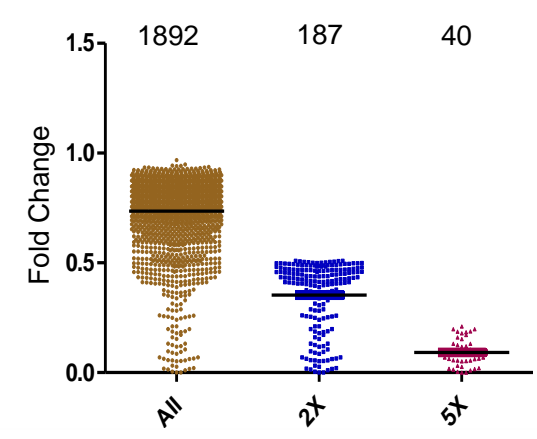

\section{4 k-means}

$\begin{array}{lll}-2 & 0 & 2\end{array}$

$1 \mathrm{Ad}$

$2 \mathrm{Ad}$

$3 \mathrm{Ad}$

$4 \mathrm{Ad}$

$5 \mathrm{Ad}$

$6 \mathrm{Ad}$

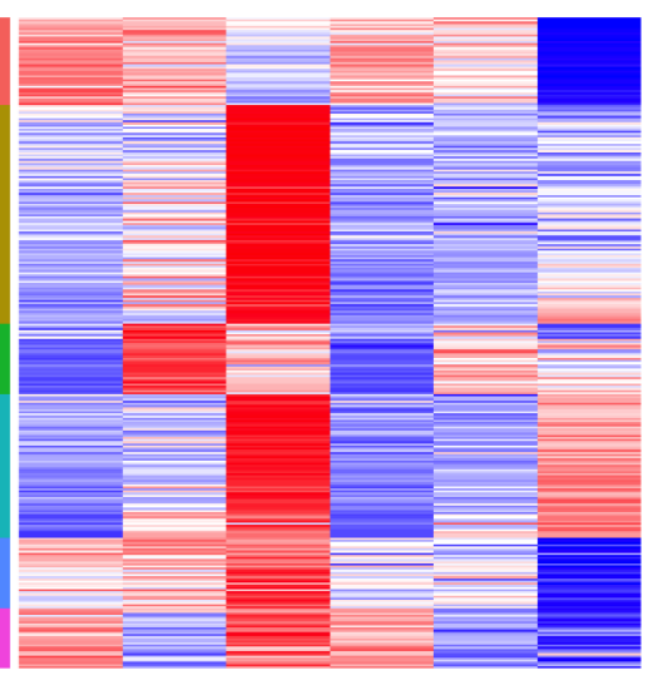

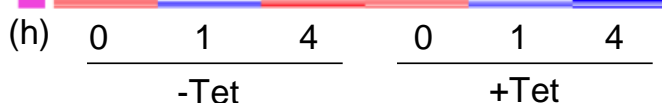

D

RELA binding, dnlkBa $\downarrow$ (304) -promoters

\begin{tabular}{|l|l|l|}
\hline Consensus sequence & P-value & Motif Name \\
\hline GGAAATTCCC & $1 \mathrm{e}-13$ & NFkB-p65-Rel \\
\hline PGGGGATTICCC & $1 \mathrm{e}-10$ & NFkB-p65 \\
\hline GGGGGATCCCC & $1 \mathrm{e}-6$ & NFkB-p50,p52 \\
\hline
\end{tabular}

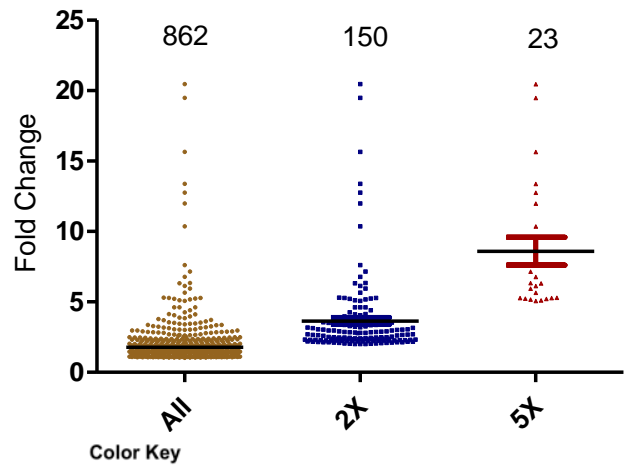

304

Hierarchical clustering

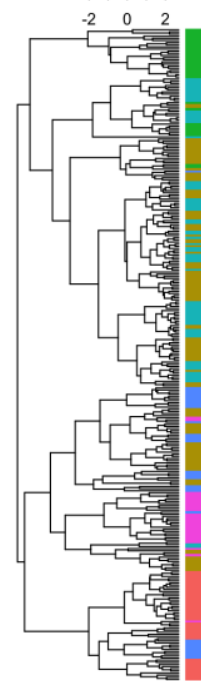

(h) 0

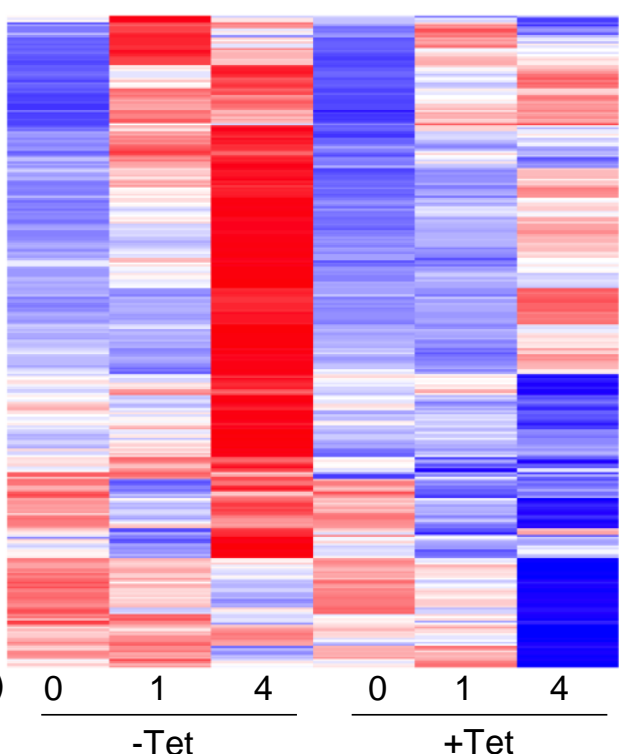

RELA binding, dnlkBa $\downarrow$ (304) -under peaks

\begin{tabular}{|l|c|l|}
\hline Consensus sequence & P-value & Motif Name \\
\hline A्AGGGATTTCCC & $1 \mathrm{e}-129$ & NFkB-p65 \\
\hline GGAAATICCC & $1 \mathrm{e}-68$ & NFkB-p65-Rel \\
\hline GGGGAATCCCC & $1 \mathrm{e}-61$ & NFkB-p50,p52 \\
\hline
\end{tabular}

$\mathrm{E}$

Under peaks (304)

\begin{tabular}{|c|c|c|c|c|}
\hline Cluster number & Consensus sequence & P-value & Motif Name & $\%$ of Targets Sequences with Motif \\
\hline \multirow[t]{3}{*}{ Patterns 2Ad,4Ad } & GGGGASTICC & 1e- 69 & REL & $33.73 \%$ \\
\hline & 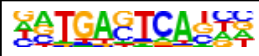 & $1 \mathrm{e}-27$ & JunB(bZIP) & $28.99 \%$ \\
\hline & AAGGGCAACT & $1 \mathrm{e}-18$ & Stpi1 & $10.65 \%$ \\
\hline \multirow[t]{2}{*}{ Pattern 3Ad } & AGGGCADTICCC & $1 e-16$ & NFkB-p65 & $42.42 \%$ \\
\hline & bZIP motif & NA & NA & NA \\
\hline
\end{tabular}


TNFAIP3
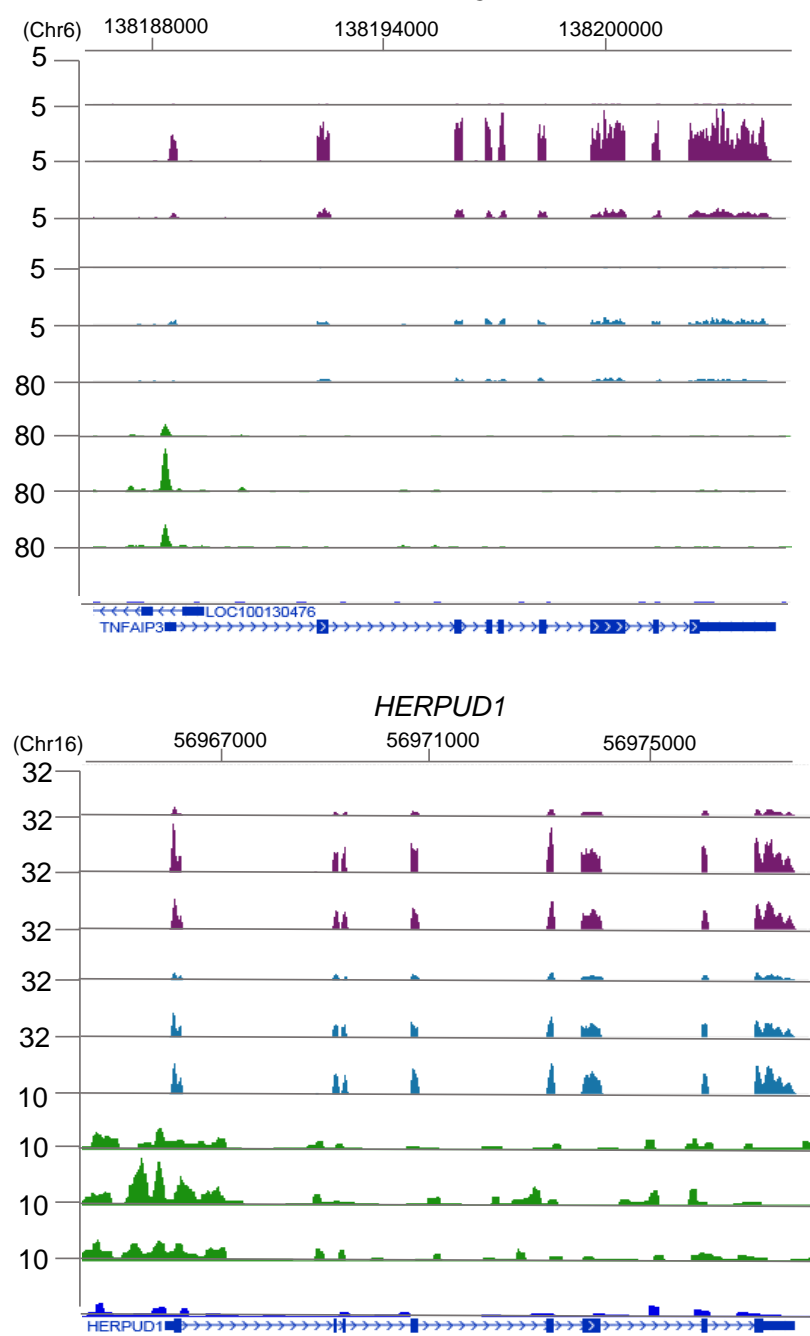

STAT5A

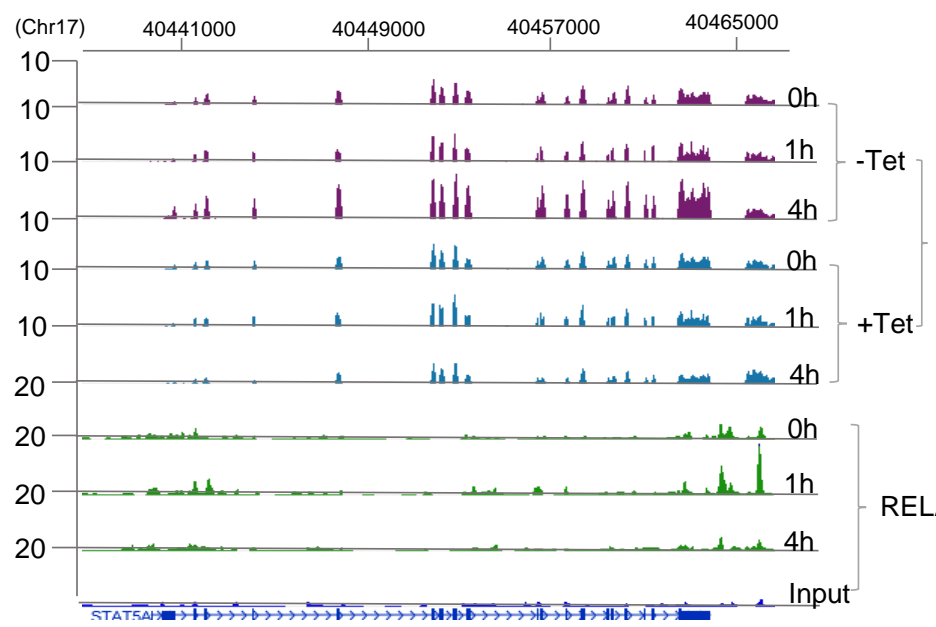

RNA

RELA

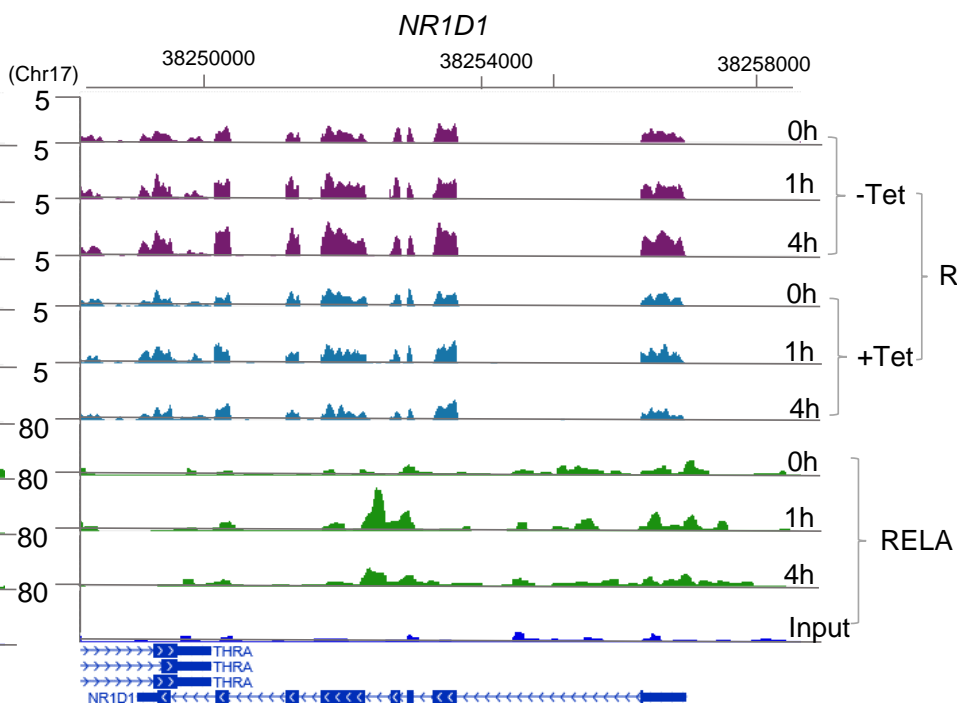

